\title{
Sistemas DE EMPREgO PÚBLICO NO SÉCULO XXI: QUE SIGNIFICADO? UMA SISTEMATIZAÇÃO
}

\author{
Pedro Nunes (pnunes@ipca.pt) \\ Escola Superior de Gestão - Instituto Politécnico do Cávado e do Ave, Portugal \\ ConCeição Castro (conceicaocastro@eu.ipp.pt) \\ Escola Superior de Estudos Industriais e de Gestão - Instituto Politécnico do Porto, Portugal \\ O presente artigo intenta sistematizar as formas ou regimes do emprego \\ público em países da Uniáo Europeia e da OCDE. A metodologia \\ compreende a análise dos tradicionais sistemas de carreira (career-based \\ system) e sistema de emprego (position-based system) no emprego público. \\ Desenvolvem-se, ainda, breves reflexóes nas mudanças operadas naqueles \\ dois regimes que migraram para um terceiro modelo, vulgarmente \\ designado por modelo híbrido de emprego público, mais flexível e mais \\ correlativo às circunstâncias do século XXI.
}

Palavras-Chave: Emprego público, carreira, flexibilidade, função pública. 


\section{PUBLIC EMPLOYMENT SYSTEMS IN XXI CENTURY: WHAT MEANS? AN SYSTEMATIZATION}

This article intends to systematize the forms or systems of public employment in EU countries and the OECD. The methodology includes the analysis of traditional career systems (career-based system) and the employment system (position-based system) on public employment. We Develop, yet, concise reflections on the changes occurred in those two schemes that have migrated to a third model, commonly called a hybrid model of public employment. This model reveals more flexible and correlative to the circumstances of the twenty-first century.

Keywords: Public employment, career, flexibility, civil service. 


\section{INTRODUÇÃO}

A gestão de recursos humanos ou, em última instância, a gestão do emprego público, em todas as suas dimensóes, tem sido nas últimas décadas razão e causa de grandes controvérsias. Emergiram várias discussões entre os académicos, em particular dos comummente conhecidos por tradicionalistas, que encaravam a reforma, ou iniciativas de reforma, como um Cavalo de Tróia camuflado de ideias ultra-liberais baseadas em cortes e custos numa lógica de mercado. Do outro lado apareceram normalmente os que condenam a natureza ultra-social dos métodos tradicionais que atacam o princípio da manutenção ou permanência dos trabalhadores, a todo o custo, e da inviolabilidade dos benefícios daqueles trabalhadores.

Apesar do que se refere, parece consensual, pelo menos para a maioria dos entusiastas daqueles argumentos, que a gestão de recursos humanos na administraçáo pública pode, eventualmente, ter efeitos perniciosos sobre o próprio funcionamento dos serviços públicos. Dir-se-á, neste entendimento, que a questão numérica e funcional e, até, dos custos com pessoal são questôes que, no âmbito das reformas, deveráo andar sempre juntas, dada a complexidade do problema. Esta ideia é, aliás, corroborada por vários e importantes investigadores (Pollitt e Bouckaert, 2004).

O Livro Verde da Comissão Europeia "Modernizar o direito do trabalho para enfrentar os desafios do século XXI” (Comissão Europeia, 2006) aparece, é pelo menos entendimento próprio, como um conjunto de princípios comuns que visam alargar o horizonte da reforma do emprego, no sentido de a náo limitar às questôes institucionais, mas também, à questão da segurança e flexibilidade dos trabalhadores. Deste modo, os componentes da reforma deverão abranger: (i) acordos flexíveis, confiáveis e aceitáveis ao nível das leis do trabalho e da negociação colectiva e, até, de formas modernas de organização do trabalho; (ii) estratégias abrangentes de aprendizagem ao longo da vida que assegurem uma contínua capacidade de trabalho aos empregados; (iii) promoção de medidas eficazes que previnam as rápidas mudanças económicas, encurtando a duração do desemprego e facilitem a transição para novos tipos de emprego; e, por último, (iv) sistemas de segurança social modernizados, com sistemas de garantias adequados e que, 
ao mesmo tempo, promovam o emprego e o apoio à mobilidade no mercado de trabalho.

Nos últimos anos, os académicos começaram por reconhecer os limites da NPHRM (New Public Human Resource Management) enquanto modelo global e que serviria para todas as situaçóes e como solução para qualquer reforma. Os primeiros a questionar tal aspiração foram Pollitt e Bouckaert (2004) e Osborne (2006). As observaçóes aos vários textos daqueles autores deixavam antever tal certeza, a de que a sociedade em geral e o sector público em particular, não estão confortáveis com o modelo (Light, 2002; Soni, 2004; Farnham, 2003, apud Desmarais, 2008).

Parece, pois, evidente, nos nossos dias, que existe uma forte tendência de ritmos bastante acelerados da flexibilidade do emprego público e, até, do emprego em geral. Os sistemas tradicionais de emprego, como toda a estrutura da administração pública, sofreram reformas administrativas, ou iniciativas de reforma, tanto no seu regime legal, como nas formas de acesso e ingresso dos recursos humanos. O tradicional sistema de carreira, comum a um grande número de países da Europa e América do Norte, parecia estar a mudar para alternativas de emprego muito mais flexível. Enquanto fenómeno recente estava a ser ajustado às necessidades extemporâneas de serviço, não duráveis, e em especial na busca de novos formatos de provisão do serviço público. Este ajustamento teve também relação, para algumas situaçóes e para alguns países, com a redefinição do papel do Estado e, por consequência, fez prevalecer, em muitas situaçóes, a ideia de que menos Estado, melhor Estado, ficando este limitado às funçóes essenciais ou, pelo menos, de soberania. Tal circunstância, muito estudada, vinha ao encontro do sistema de trabalho em sentido amplo, isto é, como nova forma de contratação e alocação de recursos humanos e financeiros até então, impensáveis e incompatíveis com o modelo burocrático de administração.

A visão (ou princípio motivador) da segurança no emprego, que não é nova, associada a redefiniçóes e redesenhemos do aparato estatal, desaparece gradualmente com a passagem de um regime de carreira (fortemente tradicional) para um regime de emprego. O emprego para toda a vida e a segurança estatutária começou, de facto, a ser fortemente questionado. Com afirma Lopes (2001) começou a falar- 
-se mais de empregabilidade e flexibilidade que, conforme se refere em textos da OCDE (apud Saraiva, 1997), inclui o conjunto de meios para melhorar a eficácia das organizaçóes e a sua capacidade para se adaptar a contextos de mudança do trabalho. A reforma do emprego público começou, assim, a ser um problema real de governação, não se reduzindo a uma solução técnico-jurídica, já que estava em questão a credibilidade da actividade pública e política, que carecia de construir consensos entre os principais actores para definir com transparência as novas regras do jogo (Menchero, 2002).

A questão central parecia ser, assim, a de se saber se era racional continuar a investir e desenvolver um sistema de carreira (career civil-service system) (Bodiguel, 1995; OECD, 1995, 1997a, 2001; Eymeri, 2001; Nomden, 2002), como foi o caso da Alemanha, Portugal e França (pelos menos durante e depois do século $\mathrm{XX}$ ) ou se, por outro lado, se deveria investir no regime de emprego (job civil-service system) como fez, desde muito cedo, o Reino Unido e a Holanda, por exemplo, dotando o aparato estatal de empregados mais qualificados e mais motivados para o esforço de modernização.

Os arranjos institucionais das formas ou sistemas de emprego público variaram, assim, entre os países da OCDE. Tais dissemelhanças verificam-se em vários aspectos. Apesar do que se expóe, a grande maioria daqueles países balança por uma das seguintes escolhas (não anulando a outra) que se resumem, portanto, a dois modelos profissionais distintos que são aplicados no emprego público: (i) o sistema de carreira (career-based system) e, (ii) o sistema de emprego (position-based system) (Dahlström et al, 2008; Demmke et al, 2008' ${ }^{1}$; Adomonis, 2008; Bour-

1 O sistema de carreira é caracterizado pela predominância da ideia de emprego para toda a vida, com critérios específicos de acesso e ingresso na função, uma forte ênfase no desenvolvimento da carreira com uma grande relevância para a antiguidade e uma diferenciação relativamente forte entre o emprego público e privado (Demmke et al, 2008). O sistema de emprego é caracterizado por um foco sobre a selecção de candidatos para cada posição, um acesso e ingresso mais aberto e uma maior mobilidade entre o emprego no sector privado e no sector público. 
gon, 2008², Kuperus et al, 200933). Os dois sistemas em confronto, variam de país para país como se disse e, não raras vezes, dentro do próprio país, conforme o nível (central, regional ou local) de administração pública.

Apesar do facto dos serviços públicos, nos países europeus, serem semelhantes nos limites da protecção dos valores e princípios fundamentais da administração pública, o desenho do emprego público apresenta uma grande diversidade e diferença de estrutura orgânica (Adomonis, 2008). Conforme refere o autor, existem vários factores que contribuem para essa falta de homogeneidade: (i) a diversidade de instituiçốes que constituem o serviço público (horizontal scope of the civil service); (ii) a abundância de posiçóes e cargos disponíveis, quer no âmbito da função política (cargos políticos de livre designação, não eleitos mas nomeados), quer no âmbito administrativo (altos cargos públicos de nomeação política) (vertical scope of the civil service); e, (iii) variedade de estatutos de emprego público que abrangem as funçóes públicas que se cometem ao Estado (material scope of civil service).

\section{SISTEMAS DE EMPREGO PÚBLICO VERSUS MODELOS DE ADMINISTRAÇÃO PÚBLICA}

É uma evidência que o modelo de emprego público adoptado, por qualquer país, tem uma relação directa com o modelo de administração pública desse mesmo país. Esta relação resulta de diversas causas. Em primeiro lugar, existem diferenças

2 Tradicionalmente, os sistemas de gestão de recursos humanos da administração pública são classificados como sistema de carreira (career-based system) ou sistema de emprego (position-based system). Em sistemas de carreira os funcionários são geralmente contratados (nomeados) no início de carreira e espera-se que permaneçam no serviço ao longo de toda a vida profissional. A entrada inicial é baseada em habilitaçóes académicas e/ou um exame de admissão ao funcionalismo público. Uma vez recrutadas, as pessoas são incorporadas em função das necessidades da organização (Bourgon, 2008). O sistema de emprego é baseado no princípio de recrutamento para habilidades e competências associadas a cargos ou a uma área específica de trabalho. $\mathrm{O}$ recrutamento pode ser feito internamente ou externamente, sem garantia de promoçóes posteriores. De um modo geral, há mais abertura nesse sistema, pois as nomeaçóes são feitas a partir de um amplo número de candidatos.

3 Para além das características anteriores, Kuperus et al (2009) acrescenta ainda as seguintes características. Para o regime de carreira: critérios de admissão específicos, baixo nível de delegação e individualizaçáo. Para o regime de emprego: acesso mais aberto e maior mobilidade entre o emprego no sector público e privado; considerável nível de delegação e individualização; avaliação e desempenho; mais fácil de se implementarem mudanças. 
entre os Estados com um sistema de emprego e um sistema de carreira porque em cada um desses sistemas as condições a aplicar aos trabalhadores também são diferentes. Em segundo lugar, e embora as estruturas da administração pública e as condições de trabalho sejam diferentes em cada país, existem certas semelhanças na organização do serviço público que pode ser visto como um cluster geográfico de cada país, decomposto em: Continental, Mediterrânico, países nórdicos e países do Leste Europeu (Kuperus et al, 2010) (tabela 1).

\section{Tabela 1}

\section{Características básicas das diferentes tradições/país}

\begin{tabular}{|c|c|}
\hline Tradição & Tradição do Serviço Público \\
\hline Continental & $\begin{array}{l}\text { Elevado status dos funcionários públicos, organizados e reconhecidos } \\
\text { como corpos especiais }\end{array}$ \\
\hline Anglo-Saxónica & Elevado status dos funcionários públicos, não são politizados \\
\hline Nórdica & $\begin{array}{l}\text { Emprego público altamente descentralizado (modelo de agência), } \\
\text { profissional e não politizado }\end{array}$ \\
\hline Mediterrânica & $\begin{array}{l}\text { Os funcionários públicos têm um baixo status, existência de intervenção } \\
\text { política na administraçáo }\end{array}$ \\
\hline Europa de Leste & $\begin{array}{l}\text { Cada país tem adoptado um sistema diferente, mas as tendências mais } \\
\text { comuns são: baixa qualidade do serviço público, mecanismos muito débeis } \\
\text { para evitar a interferência da política na administração }\end{array}$ \\
\hline
\end{tabular}

Fonte: Kuperus, H., Rode A. e Duta, R. Trends in Public Administration and the Healthcare Sector, as part of the project "Restructuring in the Public Sector: A Flexicurity Approach" (co-financed by the European Commission) apud Kuperus, et al, 2010. Tradução própria.

Nestas circunstâncias as tradiçóes dos vários países ou Estados vão influenciar, obviamente, o tipo, ou tipos, de reforma da administração pública, particularmente do emprego público, como se pode ver na tabela 2 . 
Tabela 2

Resumo dos tipos de reforma

\begin{tabular}{l|l}
\multicolumn{1}{c|}{ Tipo de reformas } & \multicolumn{1}{c}{ Países onde a reforma foi realizada } \\
Nova Gestão Pública & Países Anglo-saxónicos \\
\hline Políticas de Estado de Bem-Estar & Países Escandinavos \\
\hline $\begin{array}{l}\text { Reforma Institucional (privatização, } \\
\text { descentralização) }\end{array}$ & $\begin{array}{l}\text { França, Bélgica, Itália em certa medida, mas } \\
\text { também o leste Europeu e mediterrâneo }\end{array}$ \\
\hline Reformas Graduais (step-by-step Proceedings) & Alemanha e Holanda ('Dutch polder model') \\
\hline $\begin{array}{l}\text { Reformas político-administrativas (na } \\
\text { sequência de mudança de regime) }\end{array}$ & Países mediterrânicos e do leste europeu \\
\hline \hline
\end{tabular}

Fonte: Minogue, M., "Changing the state: concepts and practice in the reform of the public sector" (p. 17 - 37) em Minogue, M., Polidano, C. and Hulme, D., Beyond the New Public Management: Changing Ideas and Practices in Governance; Edward Elgar: Cheltenham, UK, 1998, p. 1. Apud Kuperus et al, 2009. Tradução própria.

Outro ponto de vista especial, mais dicotómico, tem a ver com o contraste do clássico sistema jurídico (ou influência) em vigor (tabela 3, 4). Assim, a relevância de diferentes tradiçóes públicas e administrativas, como o clássico contraste entre o sistema continental (direito público, direito administrativo, sistema de administração executiva) por um lado, e o sistema anglo-saxónico, sistema de administração judiciária (common law) por outro, são frequentemente encontrados na investigação sobre administração pública comparada (Demmke et al, 2008) que por sua vez, influencia o tipo de reforma. 
Tabela 3

Administração pública tradicional/país

\begin{tabular}{l|l}
\multicolumn{1}{c|}{ Administração pública (tradicional) } & \multicolumn{1}{c}{ País } \\
Tradição Anglo-Saxónica & Irlanda, Malta e Reino Unido \\
\hline Tradição da Europa Continental & $\begin{array}{l}\text { Áustria, Bélgica, França, Alemanha, } \\
\text { Luxemburgo, Holanda e Eslovénia }\end{array}$ \\
\hline $\begin{array}{l}\text { Tradição Mediterrânica/Tradição do sul da } \\
\text { Europa }\end{array}$ & Chipre, Grécia, Itália, Portugal e Espanha \\
\hline Tradição Escandinava & Dinamarca, Estónia, Finlândia e Suécia \\
\hline Tradição da Europa Continental & $\begin{array}{l}\text { República Checa, Hungria, Lituânia, Polónia, } \\
\text { Eslováquia e Lituânia }\end{array}$ \\
\hline $\begin{array}{l}\text { Novos Estados-Membros (Tradição do } \\
\text { Sudeste) }\end{array}$ & Bulgária e Roménia \\
\hline \hline
\end{tabular}

Fonte: Demmke et al, 2008. Tradução própria.

Tabela 4

Sistemas tradicionais de RH na administração pública/país

\begin{tabular}{l|l|l}
$\begin{array}{c}\text { Sistemas tradicionais de } \\
\text { RH na administraçáo } \\
\text { pública }\end{array}$ & \multicolumn{1}{|c}{ Sistema } & \multicolumn{1}{c}{ País } \\
\hline \multirow{2}{*}{$\begin{array}{l}\text { Continental } \\
\text { Mediterrânico }\end{array}$} & Carreira & Áustria, Bélgica, Alemanha, França e Luxemburgo \\
\cline { 2 - 3 } & Emprego & Holanda e Eslovénia \\
\hline Carreira & Chipre, Grécia, Espanha e Portugal \\
\hline Escandinavo & Emprego & Itália \\
\hline Europa de Leste & Carreira & Dinamarca, Estónia, Finlândia e Suécia \\
\hline Emprego & Letónia e República Checa \\
\hline Anglo-Saxónico & Emprego & Reino Unido \\
\hline Carreira & Irlanda e Malta \\
\hline Sudeste Europeu & Carreira & Bulgária e Roménia \\
\hline Outros... & Emprego & EUA \\
\hline \hline
\end{tabular}

Fonte: Demmke et al, 2008. A. Auer, Ch. Demmke, R. Polet, Civil Services in the Europe of Fifteen, Maastricht, 1996, p. 139, em Czaputowicz, 2002; OCDE, 1993, 1997a, 1997b, 2000. Adaptado. Tradução própria. 


\section{OS SISTEMAS DE EMPREGO PÚBLICO}

Sugere-se na literatura, quase por consenso nos países da OCDE, da importância da necessidade de existir um sistema de carreira (career-based) no emprego público, até pelas funçóes essenciais do Estado, apesar da hipotética discordância sobre qual o perímetro, ou qual a grandeza, deva assumir tal regime. Existem, mesmo assim, diversas e importantes opiniôes sobre o modo de atingir esse fim, uma vez que se tratam de diferentes culturas, arquétipos ou modelos de emprego público. No caso dos países da OCDE os modelos de emprego público representam um mix dos dois sistemas e a dicotomia assenta, como já se viu, entre o modelo de carreira e emprego (career based model e o position based model). A descriçâo na tabela 5 pretende esquematizar a informação (OCDE, 2008).

Ressalve-se, mesmo assim, que ao nível das nomenclaturas, os dois regimes aparecem na literatura com as subsequentes tipologias: no caso sistema de carreira (Civil Service Model) (i), aparecem as seguintes designaçóes: career based model; career-based systems; closed systems e career system; no caso do sistema de emprego (Public Employment Model) (ii), aparecem as seguintes designaçôes: position based model; position-based system; open system e position system. 
Tabela 5

Função pública e modelos de emprego público

\begin{tabular}{l|l}
\multicolumn{1}{c|}{$\begin{array}{c}\text { Modelo de serviço público } \\
\text { ou modelo de carreira }\end{array}$} & \multicolumn{1}{c}{$\begin{array}{c}\text { Modelo de emprego público } \\
\text { ou regime de emprego }\end{array}$} \\
\hline Emprego assente no Direito Público & Emprego assente no Direito Privado \\
\hline $\begin{array}{l}\text { Emprego para toda a vida } \\
\text { promoçóes reservadas por acesso interno }\end{array}$ & $\begin{array}{l}\text { Recrutamento pata categorias e postos } \\
\text { específicos, todos abertos a candidatos } \\
\text { externos }\end{array}$ \\
\hline $\begin{array}{l}\text { Ênfase nas habilitaçóes literárias e certificados } \\
\text { formais }\end{array}$ & $\begin{array}{l}\text { Toda a experiência e qualificaçôes podem ser } \\
\text { tidas em consideraçáo }\end{array}$ \\
\hline $\begin{array}{l}\text { Remuneraçáo protegida por estatuto, } \\
\text { importância da antiguidade }\end{array}$ & $\begin{array}{l}\text { Remuneração protegida por contrato, } \\
\text { desempenho e orientação para o mercado, } \\
\text { sem requisitos de antiguidade }\end{array}$ \\
\hline $\begin{array}{l}\text { Foco na lealdade, nos procedimentos e na } \\
\text { objectividade }\end{array}$ & Foco nos resultados e no desempenho \\
\hline Regimes especiais de aposentação (reforma) & $\begin{array}{l}\text { Regime de aposentação (reforma) igual ao do } \\
\text { sector privado }\end{array}$ \\
\hline \hline
\end{tabular}

Fonte: OECD, 2008. Tradução própria.

Para os países da Europa (tabela 5) os dois modelos assumem características muito semelhantes do anterior, perfazendo-se uma separação entre o designado closed system e o open system que mais não são do que a correspondência ao career based model, no primeiro caso, e o position based model, no segundo caso. 


\section{Tabela 6}

\section{Modelos de emprego público na Europa}

\begin{tabular}{l|l}
\multicolumn{1}{c|}{ Sistema fechado } & \multicolumn{1}{c}{ Sistema aberto } \\
$\begin{array}{l}\text { Recrutamento apenas para as posições de } \\
\text { ingresso e não de acesso }\end{array}$ & $\begin{array}{l}\text { Recrutamento para categorias de ingresso e } \\
\text { de acesso (dentro da carreira) }\end{array}$ \\
\hline $\begin{array}{l}\text { Diplomas e background educacional } \\
\text { específico para carreiras específicas }\end{array}$ & $\begin{array}{l}\text { Sem diplomas e background educacional } \\
\text { específico, mas habilidades e competências } \\
\text { específicas para determinadas categorias }\end{array}$ \\
\hline $\begin{array}{l}\text { Ausência de reconhecimento de experiência } \\
\text { profissional fora do sector público }\end{array}$ & $\begin{array}{l}\text { Reconhecimento de experiência profissional } \\
\text { fora do sector público }\end{array}$ \\
\hline Procedimentos formais de recrutamento & $\begin{array}{l}\text { Sem procedimentos formais de métodos de } \\
\text { selecção }\end{array}$ \\
\hline $\begin{array}{l}\text { Período de treino e formação para os } \\
\text { iniciantes }\end{array}$ & $\begin{array}{l}\text { Sem período de treino e formação para os } \\
\text { iniciantes }\end{array}$ \\
\hline Permanente tenure & Ausência de tenure \\
\hline Regime estatutário de remuneraçóes & $\begin{array}{l}\text { Regime de remunerações de base de } \\
\text { negociação colectiva }\end{array}$ \\
\hline $\begin{array}{l}\text { Existência de uma escala salarial para } \\
\text { promoçóes e progressóes }\end{array}$ & Sem sistema de progressóes \\
\hline Sistema de antiguidade & Sem sistemas de antiguidade \\
\hline Regulamentação especial para a negociação & $\begin{array}{l}\text { Negociação colectiva feita nos mesmo moldes } \\
\text { que o sector privado }\end{array}$ \\
\hline \hline
\end{tabular}

Fonte: A. Auer, Ch. Demmke, R. Polet, Civil Services in the Europe of Fifteen, Maastricht, 1996, apud Czaputowicz, Jacek (2002). Tradução própria.

Assim, não restam dúvidas de que o sistema de emprego público (função pública, Civil Service System) está dividido em duas grandes categorias: o modelo de carreira (ou "closed" systems) e o modelo de emprego (ou "open" systems) (Bekke, Perry e Toonen, 1996; Lægreid and Wise, 2007) (tabela 6), embora, como já se tenha referido, com especificidades diferentes (tabela 7). 


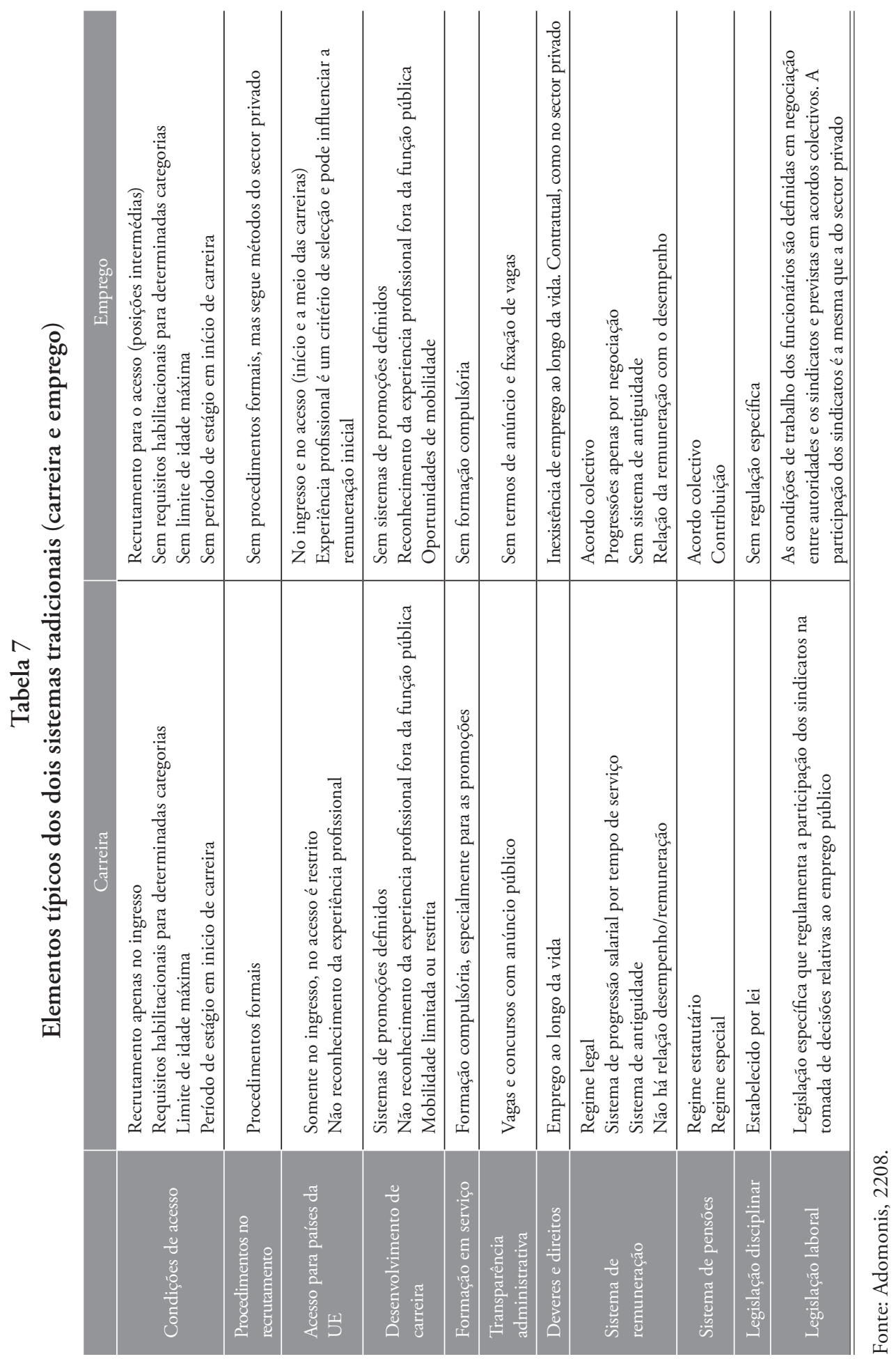


O sistema de carreira ${ }^{4,5}$ foi adoptado pela maioria dos países europeus e latinoamericanos, assim como o Japão (Saraiva, 1997). Os EUA optaram pelo sistema de emprego, onde a qualificação requerida para ocupar um posto deve responder à descrição de postos (job descripton) (Saraiva, 1997). Em França propôs-se reservar o sistema de carreira aos que realizam funçóes tipicamente estatais e deixar as restantes para o sistema de emprego.

O argumento para a opção do modelo de serviço público de carreira e, por consequência, estatutário, foi o de preservar o carácter do serviço na relação jurídica entre o empregador e o empregado, e para evitar as divergências que seriam percebidas como injustas e que prejudicariam internamente a mobilidade entre as diferentes administraçóes públicas no país e de algum modo preservar, essencialmente, as funçôes de soberania e de segurança do Estado, embora esta última razão seja muito discutida.

Deste modo, durante décadas acreditou-se que os modelos em confronto, com predominância para o modelo de carreira (fechado) protegiam de alguma maneira os valores fundamentais do serviço público e assim parecia estar encontrada a melhor maneira de preservar a ética que se pretendia para a satisfação das necessidades colectivas essenciais da parte do Estado. Apesar dessa convicçâo, muito cedo, pelas razóes que se expuseram, os limites daquele alcance de alguma foram prescreveram no tempo e na eficácia que se pretendia em relação aos modelos. De

4 Tipicamente estatais: defesa, política, diplomacia, justiça e finanças (Saraiva, 1997).

5 Segundo o modelo de Derlien (1994) e Parrado (1996) existem quatro tipos fundamentais de carreira: (i) carreira pura (implica, um indivíduo, estar na administração pública desde o começo da actividade, ou pelo, menos até 4 anos após terminar estudos); (ii) carreira retardada (a incorporação na administração pública tem lugar 4 a 7 anos posteriores ao desempenho de um primeiro posto de trabalho alheio à administração pública); (iii) carreira mista (o exercício de funçôes públicas acontece em simultâneo como exercício de funçóes privadas, ou entrar na administração pública depois de 7 anos noutra actividade profissional privada); e, (iv) carreira paralela (que se refere à ocupação sucessiva de postos de trabalho em que não se obteve ou adquiriu alguma experiência na gestáo de recursos públicos). No final as formas adoptadas por vários países para organizarem os seus serviços públicos ou funcionários públicos podem ser agrupados em dois grandes sistemas: o sistema de emprego de um sistema de carreira, o serviço tradicional ocidental (Auer, 1998). Longo (2001) afirma que a fundamental distinção entre o sistema de carreiras e sistema de emprego é no relacionamento com o mercado de trabalho. A ideia de estabilidade tem surgido como uma reacção ao sistema de despojos e contra o patrimonialismo (Saraiva, 1997), a carreira aparece como um elemento central de distinçáo entre os sistemas de emprego no serviço público. 
um modo geral, o bom funcionamento das organizaçóes não dependia já tanto, como se pensava, no desenho institucional e formal das relaçóes contratuais entre empregador e empregado mas da existência de contratos relacionais (relational contracts) (Williamson, 1975) ou contratos psicológicos (psychological contracts) (Levi, 2005) entre eles, ou seja, de intercâmbios informais que tornam possível uma acumulação de confiança (Dahlström et al, 2008). A exteriorização deste paradigma trouxe uma certeza ou, pelo menos, uma realidade que se teimava ocultar: a existência de uma enorme desconformidade no tradicional formato de encarar a gestão do emprego público. Os modelos tradicionais estáo, agora, perante uma nova visão do problema, mais aberta, muito mais próxima do sector privado que alguma vez se imaginou, apesar de não ser recente este recurso a formas de "relational contracts", uma vez que nos últimos vinte anos, um significante número de países se abriu à contratação para os serviços públicos, quer através da evolução para sistemas de emprego com recrutamento aberto a candidatos fora da função pública (outsiders), para imensos cargos e categorias; recurso ao agenciamento; e, pela reestruturação do próprio sistema de carreira e que, ainda, a permissão de entradas laterais (fora da função pública) para os cargos dirigentes ou de chefia intermédia e superiores (OECD, 2008). Esta situação estendeu-se, até, aos países mais tradicionais que têm sistemas relativamente fechados, como por exemplo, a Bélgica, França, Portugal, Irlanda e Coreia, onde o recrutamento de grande parte dos cargos de nível sénior (dirigentes) foi aberto aos candidatos provenientes do sector privado.

Como resultado de uma ampla gama de outras reformas na maioria das administraçôes públicas na última década, não há, no início do século XXI, um modelo de emprego público que possa ser descrito como "um modelo clássico da carreira” (Demmke et al, 2008), aquelas mudanças (reformas) viriam a influenciar a reclassificação dos modelos de emprego público já expostos. Nesta decorrência, reconhece-se que os dois os modelos de emprego público mais tradicionais têm as suas falhas e preocupaçóes de muito curto prazo.

$\mathrm{Na}$ prática, os modelos de emprego público começam a migrar para formatos mais híbridos em que existe um mix das mais convenientes características do sistema de emprego e do sistema de carreira (tabela 8). Este sistema está já presente nos países do Leste Europeu que iniciaram o processo de reforma da administra- 
ção pública na altura de mudança do regime. Estes sistemas híbridos começam também a aparecer em Itália e Malta (Kuperus, 2009).

\section{Tabela 8}

Estados membros com sistema de carreira, emprego e híbrido

\begin{tabular}{c|c|c}
\hline Carreira & Híbrido & Emprego \\
Áustria & & \\
Bélgica & Bulgária & \\
Chipre & Hungria & República Checa \\
França & Itália & Dinamarca \\
Elemanha & Letónia & Estónia \\
Grécia & Lituânia & Finlândia \\
Irlanda & Malta & Holanda \\
Luxemburgo & Polónia & Suécia \\
Portugal & Eslováquia & Reino Unido \\
Roménia & Eslovénia & \\
\hline \hline
\end{tabular}

Fonte: Kuperus, H., Turchetti, C., Rode, A., Recruitment and Equal Opportunities Systems in National, European and International Civil Services; European. Parliament, Policy Department for Citizens' Rights and Constitutional Affairs, November 2008. Apud Kuperus et al, 2010. Tradução própria.

Um dos factores que teve, desde início, visibilidade na opção por novos formatos de emprego público, isto é, pelo ligeiro, mas crescente, abandono do sistema de carreira, como preferência a sistemas abertos, foi a ocorrência em alteraçóes nos procedimentos ao nível do recrutamento para o emprego público.

O processo de recrutamento era o apoio mais importante para aquela dicotomia existente nos modelos. Assim, o sistema, em princípio "aberto" a todos os que se qualificam para o cargo, e não apenas aos empregados oriundos da função pública (Dahlström et al, 2008) foi, talvez, o primeiro passo para o crescente interesse na gestão estratégica de recursos humanos nos últimos 20 anos, como justifica um corpo considerável de pesquisas que tem emergido com preocupação nos aspectos funcionais da gestão de recursos humanos. Apesar disso, e embora grande 
parte da literatura prescritiva defenda um papel cada vez mais estratégico (Ulrich, 1998, apud Dahlström et al, 2008), os resultados empíricos têm sido ambivalentes sobre a possibilidade, ou não, dos departamentos de RH terem (ou serem) sido capazes de alcançar aquele objectivo, em especial no sector público (Kessler, Purcell e Coyle Shapiro, 2000; Harris, 2002; Caldwell, 2003, apud Truss, 2009). A entrada de outsiders na função pública é, ainda, um assunto sensível, apesar das vantagens que se the reconhece.

Mastracci et al (2007) analisou e relançou para a discussão o fenómeno da flexibilização do trabalho no sector público nos EUA, e descreveu vários factores que reclamam o uso de contratos de trabalho náo padronizados para aquele sector. Notou, em primeira mão, observando as dinâmicas políticas, que era necessário uma maior utilização de funcionários contratados por agência públicas a par de um maior controlo de efectivos, requisito especial, e politicamente conveniente, desde os anos 80 dada a animosidade com o chamado "big government". Em segundo lugar, a contratação de serviços fora do governo ou da administração pública permitiria que as agências do governo pudessem obter conhecimento qualificado e experiência nos empregados a recrutar, que é particularmente desejável quando certas capacidades são necessárias apenas temporariamente, ou pelo menos, não numa base regular e contínua, tais como serviços de tecnologia de informação e comunicação. Embora a abordagem do modelo de emprego (sistema aberto) fosse realizada usando o tipo de linguagem do sector privado, há alguns autores que consideram que há o perigo das organizaçóes do domínio público negligenciarem os valores inerentes a esse domínio (Stewart e Walsh, 1992, apud Boyne et al, 1999).

Estudos anteriores compararam as várias dimensões do sector público e privado. Uns dedicaram-se às dinâmicas dos sindicatos que mostraram um declínio no sector privado, mas nenhuma mudança no sector público (Fiorito et al., 1996; Deery e De Cieri, 1991; Bain e Price, 1993, apud Harel et al, 2001). Outros (notados em Harel et al, 2001) observaram as diferenças nas práticas de gestáo (Clark et al., 1994) e o sucesso ou o fracasso da execução de políticas de qualidade (Se-Jeong, 1991). Vandenheuvel (1994) e Madeira (1990) exploraram a questão do absenteísmo e encontraram uma maior taxa de absentismo na função pública. Shapiro e Steiner (1989) estudaram o diferencial de rendimentos entre os dois 
sectores. Da mesma forma, foram encontradas diferenças nos benefícios pagos aos empregados (Dubin e Aharoni, 1981; Milkovich e Newman, 1990). Contudo, outro estudo encontrou diferenças nas estratégias de recrutamento dos dois sectores (Sziraczki e Windell, 1995). Embora uma quantidade considerável da pesquisa tenha comparado diversas práticas organizacionais nos sectores público e privado, "nenhuma tentativa foi feita para comparar as práticas de GRH na íntegra” (Harel et al, 2001).

Conclui-se, assim, que o contributo de novas formas de recrutamento, em especial a permissão de outsiders, levou à náo existência de modelos puros de carreira e emprego (Demmke et al, 2008). Como alternativa e como já se referiu, parece haver uma tendência para sistemas híbridos que combinam elementos de ambos os sistemas puros. Uma análise, realizada por Demmke et al (2008), dos diferentes sistemas nacionais de $\mathrm{RH}$ com base em 17 indicadores/características, mostrou que ainda existem diferenças consideráveis entre os sistemas de recursos humanos em diversos países (tabela 9).

Tabela 9

Sistema de RH por país

\begin{tabular}{|c|c|}
\hline Sistema de Recursos Humanos & País \\
\hline Carreira (Career-based HR system) & $\begin{array}{l}\text { Áustria, Bélgica, Bulgária, Chipre, França, } \\
\text { Alemanha, Grécia, Hungria, Irlanda, } \\
\text { Lituânia, Luxemburgo, Malta, Polónia, } \\
\text { Portugal, Roménia, Eslováquia e Espanha }\end{array}$ \\
\hline Emprego (Position-based HR system) & $\begin{array}{l}\text { República Checa, Dinamarca, Estónia, } \\
\text { Finlândia, Itália, Letónia, Holanda, } \\
\text { Eslovénia, Suécia e Reino Unido }\end{array}$ \\
\hline
\end{tabular}

Fonte: Demmke et al, 2008.

Há, pois, uma tendência crescente dentro de um número também crescente de Estados-Membros da UE para combinar elementos típicos de ambos os sistemas (Adomonis, 2008) e torná-los, como se viu (tabela 8) em modelos híbridos, enquanto combinação dos dois sistemas. Em qualquer caso, as mudanças na configuraçáo dos serviços públicos são direccionados principalmente para o sistema de emprego uma vez que é mais flexível, consequentemente, mais barato. 
A utilização da abordagem da flexisegurança na administração pública é difícil e mais desafiadora do que no sector privado, até pelas diferenças organizacionais, estruturais e, até, de valores (Kuperus et al, 2010) mas um conjunto de países estâo efectivamente a operar um regime híbrido de emprego público que combina com algumas características daquela teoria (flexisegurança) e, ainda, em alguns aspectos que tem a ver, de resto, com o tipo de ênfase que o próprio país dá a determinadas características (tabela 10) dos vários modelos de emprego público (Bourgon, 2008).

Tabela 10

Recrutamento para a função pública: diferenças de ênfase

Ênfase na competiçáo por categorias e experiência profissional

Austrália, Canada, Dinamarca, Finlândia, Islândia, Nova Zelândia, Noruega, Suécia, Suíça, Reino Unido e Estados Unidos da América
Ênfase no concurso e no exame e requisitos habilitacionais à entrada

República Checa, França, Hungria, Irlanda, Japão, Coreia, Luxemburgo, Espanha

Fonte: Bourgon, 2008. Tradução própria.

\section{O SIGNIFICADO DO SISTEMA DE EMPREGO PÚBLICO NO SÉCULO XXI}

Numa primeira fase (décadas de 70 e 80 ) a reforma do emprego público caracterizou-se, essencialmente, pela ênfase na reestruturaçáo do próprio serviço público. Dir-se-á que a preocupação era essencialmente orgânica e não funcional. Destacam-se, nesta fase, as reformas macroeconómicas vocacionadas para os ajustes estruturais dos problemas da máquina fiscal. Numa segunda fase (década de 90) a preocupação recaiu na avaliação da conveniente capacidade do emprego público, isto é, pela melhor forma de racionalizar a máquina do Governo (muito no seguimento das décadas anteriores). Numa terceira fase (década de 2000) o foco recaiu sobre a qualidade do serviço prestado pelo emprego público. 
São de destacar, em particular, algumas intervençóes chave da segunda fase (OCDE, 2002): (i) reforçar as competências dos trabalhadores; (ii) melhoria da gestão dos sistemas e estruturas; (iii) reconstituir os incentivos e melhorar os sistemas de pagamento; e, (iv) melhorar o ambiente de trabalho.

A melhoria prestada pelos serviços públicos passaria, assim, por seis factores de fundamentais: (i) premência da necessidade de evidenciar resultados; (ii) procura de transparência e responsabilização dos serviços públicos; (iii) transição para economias de mercado e crescimento liderado pelo sector privado; (iv) a influência da nova gestão pública; (v) a necessidade de políticas em PRH para apoiar as abordagens sectoriais; e, (vi) a prossecução de uma abordagem de sistemas de emprego integrados (OCDE, 2002).

É, aliás, este último factor a razão de grandes de dores de cabeça para a maioria dos países, no que concerne à reforma do emprego público: a aproximação do sistema de carreira ao sistema de emprego. Nesta decorrência, em início do século XXI, os investigadores das ciências administrativas "estấo cada vez mais preocupados com a proeminente inflexibilidade dos modelos organizacionais e comportamentais do sector público, não importando se foram (ou não), influenciados pela Teoria Burocrática (Bureaucratic Theory), as ideias da Teoria da Escolha Pública (Public Choice) ou a abordagem da Nova Gestão Pública (New Public Management) (Madureira et al, 2010).

As relaçôes de trabalho no serviço público sofriam, assim, alterações profundas em muitos países, nas últimas três décadas (Bordogna, 2008). Como resultado, alguns daqueles países registaram um aumento de conflitos laborais no serviço público, uma situação que muitas vezes trouxe a agenda de reforma das relaçóes de trabalho do serviço público para o centro das atençôes no cenário das relaçóes industriais nacionais. 


\section{Tabela 11}

\section{Aproximaçóes tradicionais do sistema de regulação do emprego público}

\begin{tabular}{|c|c|}
\hline $\begin{array}{c}\text { Sistema do empregador soberano (Sovereign } \\
\text { employer) }\end{array}$ & $\begin{array}{l}\text { Sistema do Empregador modelo (Model } \\
\text { employer) }\end{array}$ \\
\hline $\begin{array}{l}\text { O governo age como "empregador } \\
\text { soberano", de forma unilateral, pela } \\
\text { determinaçáo por lei e decretos, os termos e } \\
\text { condiçóes do emprego (incluindo salários) } \\
\text { dos funcionários públicos, ou pelo menos } \\
\text { uma parte substancial deles (funcionários e } \\
\text { parte dos funcionários públicos) }\end{array}$ & \multirow{2}{*}{$\begin{array}{l}\text { O governo como empregador fornece uma } \\
\text { "liderança pelo exemplo" em matéria de } \\
\text { emprego e relaçóes de trabalho, a concessão de } \\
\text { melhores elementos processuais e materiais do } \\
\text { que as praticadas no sector privado: a segurança } \\
\text { do emprego, pensôes e benefícios de faltas } \\
\text { formais, os mecanismos processuais para lidar } \\
\text { com despedimentos e processos disciplinares, } \\
\text { a formação, a antiguidade e a importância da } \\
\text { comparabilidade dos padróes nacionais }\end{array}$} \\
\hline $\begin{array}{l}\text { Prerrogativas especiais, processuais e } \\
\text { materiais, e às vezes um estatuto formal } \\
\text { especial, para uma grande parte dos } \\
\text { trabalhadores, tais como: a segurança do } \\
\text { emprego; garantias formais nos processos de } \\
\text { recrutamento, carreira, mobilidade interna, } \\
\text { as questóes disciplinares; importância } \\
\text { da antiguidade; importância das normas } \\
\text { nacionais }\end{array}$ & \\
\hline $\begin{array}{l}\text { Inexistência do direito de negociação } \\
\text { colectiva dos funcionários públicos e (pelo } \\
\text { menos em parte) e restantes trabalhadores } \\
\text { da administração pública, com limitaçóes }\end{array}$ & $\begin{array}{l}\text { Misto de regulamentação dos termos e } \\
\text { condiçôes de emprego e direito à negociação } \\
\text { colectiva } \\
\text { Modalidades de participação do empregado }\end{array}$ \\
\hline $\begin{array}{l}\text { Nenhum direito à greve ou regulamentação } \\
\text { especial }\end{array}$ & $\begin{array}{l}\text { Direito à greve, por vezes com algumas } \\
\text { limitaçôes }\end{array}$ \\
\hline Admitido (em geral) o direito de associação & $\begin{array}{l}\text { Direito de associação admitido, com o apoio } \\
\text { dos sindicatos }\end{array}$ \\
\hline
\end{tabular}

Fonte: Bordogna, 2008

No que diz respeito, mais especificamente, às relaçóes de emprego e políticas dos trabalhadores, as implicaçóes dessas ideias e normas eram essencialmente para defrontar ambas as abordagens tradicionais de regulação de serviços públicos, que dominaram as democracias mais industrializadas nos pós guerra. Ou seja, por um lado, a abordagem do "empregador soberano" (tabela 11), típica da tradição Alemã e Austríaca, bem como (com algumas especificações) de outros países europeus continentais (como a França, mas também a Dinamarca, a Espanha e ainda outros) e, por outro lado, o "empregador modelo", abordagem típica da tradição Anglo-Americana (Beaumont, 1992; Bach e Kessler, 2007, apud, Bordogna, 2008). 
Estas duas abordagens são diferentes nalguns aspectos importantes, nomeadamente com referência ao papel de regulação unilateral versus conjunto dos termos e condiçóes de trabalho, e a questão ligada à proibição/limitação versus o reconhecimento do direito à greve. Mas, e apesar das diferenças, têm também várias características em comum:

i) algumas formas de segurança do trabalho (mais rigorosas na primeira abordagem);

ii) garantias materiais e processuais em matéria de recrutamento, mobilidade interna, carreiras, formação e questôes disciplinares;

iii) a importância da antiguidade e tempo de serviço na determinação dos salários e carreiras, com referência a alguns padróes de comparabilidade nacional;

iv) atenção para as questóes de equidade, o respeito pela competência profissional e tradiçóes; e,

v) importância e status do funcionário público (Bordogna, 2008). Como consequência da nova abordagem, o autor menciona um conjunto de efeitos sobre o mercado de trabalho do sector público e das relaçóes de trabalho que podem ser esperados (Bordogna, 2008):

a) uma diminuição da quota de emprego no sector público trazida pela privatização generalizada e outsourcing de processos, bem como por crescentes preocupações sobre a contenção da despesa pública;

b) um decréscimo de empregados do sector público que gozam do estatuto profissional especial e um aumento paralelo dos trabalhadores com contratos de trabalho comuns, e também do contingente de trabalhadores, em consequência do objectivo mais vasto para diminuir ou eliminar a diferença entre o sector público e o sector privado;

c) uma redução do alcance e da intensidade das prerrogativas associadas ao estatuto especial de trabalho, menos segurança de emprego, mas também um enfraquecimento ou eliminação de procedimentos especiais em caso de despedimentos e de garantias formais (recrutamento, carreiras, mobilidade horizontal e questóes disciplinares, bem como regimes de pensões menos favorável); 
d) uma ampla difusão de "negociação colectiva" livre (isto é, numa base voluntária), como o principal método de regulação da relaçẫo de trabalho, em detrimento de formas com base legal de regulaçáo unilateral;

e) descentralização da negociação colectiva, como maneira mais sensível às variaçôes das condiçôes locais do mercado de trabalho e necessidades organizacionais, em detrimento de formas nacionais de todos os serviços públicos;

f) importância da diminuição ou supressão do tempo de serviço ou outros requisitos automáticos e "colectivistas", como os critérios para determinar os aumentos salariais e de carreira, em favor de um mecanismo mais diferenciado, flexível, selectivo e individualizado, tal como formas de concurso público para as promoçóes na carreira ou em vários tipos de mérito e pagamento (salário) indexado ao desempenho; e,

g) uma abordagem menos preconceituosa favorável a sindicatos e sindicalismo, e nalguns casos orientada para o confronto, no âmbito do reforço das prerrogativas em matéria de gestáo de pessoal.

\subsection{Representaçáo dos modelos de emprego público versus flexibilida- de e segurança}

Os cidadãos estão cada vez mais críticos e exigentes quanto ao desempenho e integridade dos serviços e funcionários públicos (Demmke et al, 2008). Já não se exige apenas elevada qualidade do serviço mas, também, transparência, controlo, integridade, flexibilidade, etc.. Colocar-se-ão grandes questóes e desafios no futuro do emprego público. Cada país estará à procura de instrumentos ajustados para enfrentar aqueles desafios futuros, ou seja, tornando o mercado de trabalho mais adaptável às rápidas mudanças.

Como refere Kuperus et al (2010) exige-se a integração do conceito de flexisegurança (um equilíbrio entre flexibilidade e segurança) nas políticas governamentais e que serão úteis no desenvolvimento de estratégias de mercado sustentáveis para o emprego público. Este equilíbrio entre flexibilidade e segurança mais não é, quanto a nós, que o correspondente mix do modelo de carreira e emprego, isto, 
é, de um modelo mais híbrido e que combine as características mais importantes no alcance do equilíbrio e, ao mesmo tempo, de segurança.

O conceito de flexisegurança $a^{6}$ enfatiza a flexibilidade no mercado de trabalho, em particular no emprego público que agora se trata, conquanto, garanta da mesma maneira a segurança nas mudanças dos trabalhadores de um categoria/cargo/ posição para outro (a), tanto ao nível interno como ao nível externo (tabela 12).

6 Segundo Kuperus (2008) a flexisegurança é uma estratégia integrada, construída para lidar com diferentes tipos de desafios nas organizaçóes e no mercado de trabalho e, portanto, também pode ser ajustada para os problemas específicos levantados pela actual crise económica. O conceito de flexisegurança enfatiza a flexibilidade dos mercados de trabalho, assegurando uma transiçáo segura para os trabalhadores durante a sua vida: da escola para o trabalho, a partir de um emprego ou de uma posição para outra, entre o desemprego ou inactividade e de trabalho e do trabalho para a reforma/aposentação. A segurança é mais do que apenas a segurança do emprego: trata-se de capacitar as pessoas para o progresso na sua vida profissional (...). 


\section{Tabela 12}

Matriz da flexisegurança

\begin{tabular}{|c|c|c|c|c|}
\hline $\begin{array}{l}\text { Segurança } \\
\text { Flexibilidade }\end{array}$ & $\begin{array}{l}\text { Segurança no } \\
\text { trabalho }\end{array}$ & $\begin{array}{c}\text { Segurança no } \\
\text { emprego }\end{array}$ & $\begin{array}{l}\text { Segurança nos } \\
\text { rendimentos }\end{array}$ & $\begin{array}{l}\text { Segurança } \\
\text { combinada }\end{array}$ \\
\hline $\begin{array}{l}\text { Flexibilidade } \\
\text { numérica } \\
\text { externa }\end{array}$ & $\begin{array}{l}\text { Tipos de } \\
\text { contrato de } \\
\text { trabalho } \\
\text { Legislaçáo } \\
\text { relativa à } \\
\text { protecçáo do } \\
\text { emprego } \\
\text { Reforma } \\
\text { antecipada }\end{array}$ & $\begin{array}{l}\text { Serviços de } \\
\text { emprego } \\
\text { Formação/ } \\
\text { aprendizagem } \\
\text { ao longo da } \\
\text { vida }\end{array}$ & $\begin{array}{l}\text { Seguro/ } \\
\text { desemprego } \\
\text { Outros } \\
\text { benefícios } \\
\text { sociais } \\
\text { Salários } \\
\text { mínimos }\end{array}$ & $\begin{array}{l}\text { Protecção } \\
\text { contra o } \\
\text { despedimento } \\
\text { durante a } \\
\text { licença de vários } \\
\text { regimes }\end{array}$ \\
\hline $\begin{array}{l}\text { Flexibilidade } \\
\text { numérica } \\
\text { interna }\end{array}$ & $\begin{array}{l}\text { Regime de } \\
\text { semana de } \\
\text { trabalho } \\
\text { abreviada / } \\
\text { tempo parcial }\end{array}$ & $\begin{array}{l}\text { Legislação } \\
\text { relativa à } \\
\text { protecção do } \\
\text { emprego } \\
\text { Formação/ } \\
\text { aprendizagem } \\
\text { ao longo da } \\
\text { vida }\end{array}$ & $\begin{array}{l}\text { Part-time } \\
\text { (benefício } \\
\text { complementar) } \\
\text { Bolsas de } \\
\text { Estudo } \\
\text { Benefícios na } \\
\text { doença }\end{array}$ & $\begin{array}{l}\text { Tipos diferentes } \\
\text { de regime de } \\
\text { licenças } \\
\text { Reforma por } \\
\text { tempo parcial }\end{array}$ \\
\hline $\begin{array}{l}\text { Flexibilidade } \\
\text { funcional }\end{array}$ & $\begin{array}{l}\text { Enriquecimento } \\
\text { do trabalho } \\
\text { Formação } \\
\text { Subcontratação } \\
\text { Outsourcing }\end{array}$ & $\begin{array}{l}\text { Formação/ } \\
\text { aprendizagem } \\
\text { ao longo da } \\
\text { vida } \\
\text { Rotação } \\
\text { Trabalho em } \\
\text { equipa } \\
\text { Multi- } \\
\text { qualificação }\end{array}$ & $\begin{array}{l}\text { Remuneração } \\
\text { alocada ao } \\
\text { desempenho }\end{array}$ & $\begin{array}{l}\text { Regime de } \\
\text { tempo de } \\
\text { trabalho } \\
\text { voluntário }\end{array}$ \\
\hline $\begin{array}{l}\text { Custos do } \\
\text { trabalho/ } \\
\text { flexibilidade } \\
\text { salarial }\end{array}$ & $\begin{array}{l}\text { Ajustes nos } \\
\text { custos do } \\
\text { trabalho } \\
\text { Escalas/redução } \\
\text { dos pagamentos } \\
\text { à segurança } \\
\text { social }\end{array}$ & $\begin{array}{l}\text { Alteraçóes nos } \\
\text { pagamentos à } \\
\text { segurança social } \\
\text { Emprego } \\
\text { subsidiado } \\
\text { Benefícios no } \\
\text { trabalho }\end{array}$ & $\begin{array}{l}\text { Acordos salariais } \\
\text { colectivos } \\
\text { Benefício } \\
\text { ajustado para } \\
\text { a semana } \\
\text { de trabalho } \\
\text { reduzida }\end{array}$ & $\begin{array}{l}\text { Regime de } \\
\text { tempo de } \\
\text { trabalho } \\
\text { voluntário }\end{array}$ \\
\hline
\end{tabular}

Fonte: Wilthagen, T., Tros, F., The concept of 'flexicurity': A new approach to regulating employment and labour markets, TRANSFER - European Review of Labour and Research, 10(2), 2004, apud Kuperus et al, 2010. Tradução própria.

A matriz de flexisegurança no emprego público contém vários indicadores que ajudam a descrever a condição do mercado de trabalho, em particular, na função pública, quer do lado da flexibilidade, quer do lado da segurança. Sugere-se 
que aqueles indicadores possam coexistir, isolada ou separadamente, de forma a alcançar o conjunto de políticas necessárias a cada país tendo em conta o aparato do seu mercado de trabalho (Kuperus et al, 2010). O autor (2010) assume que os componentes fundamentais da flexisegurança são: (i) disposiçóes contratuais flexíveis e fiáveis (flexible and reliable contractual arrangements); (ii) aprendizagem abrangente ao longo da vida (comprehensive lifelong learning); (iii) mercado de trabalho efectivo e activo (effective active labour market); e, (iv) sistemas de segurança social modernos (modern social security systems). Kuperus apresenta três tipos de países, por consequência três tipos de mercado, categorizados na base do seu sistema de emprego público (tabela 13): 
Tabela 13

\section{Agrupamento de países em três tipos do mercado de trabalho}

\begin{tabular}{|c|c|c|}
\hline $\begin{array}{l}\text { Tipo de } \\
\text { mercado de } \\
\text { trabalho }\end{array}$ & Principais características do sistema & Países pertencentes \\
\hline Tipo 1 & $\begin{array}{l}\text { Muito seguro, principalmente um } \\
\text { modelo de emprego baseado no } \\
\text { sistema de carreira; elevado nível } \\
\text { de segurança no emprego para os } \\
\text { trabalhadores que têm contratos } \\
\text { permanentes de trabalho ao longo da } \\
\text { vida }\end{array}$ & $\begin{array}{l}\text { Áustria, Bélgica, Chipre, França, } \\
\text { Alemanha, Grécia, Irlanda, } \\
\text { Luxemburgo, Roménia e Espanha. } \\
\text { Também Itália e Malta com sistemas } \\
\text { híbridos de emprego público. } \\
\text { Portugal é um exemplo de país que } \\
\text { tem um sistema de carreira mas que } \\
\text { lentamente está a mudar para um } \\
\text { sistema de emprego, introduzindo } \\
\text { elementos de flexisegurança }\end{array}$ \\
\hline Tipo 2 & $\begin{array}{l}\text { Um melhor equilíbrio entre } \\
\text { flexibilidade e segurança; menor } \\
\text { mobilidade interna no âmbito do } \\
\text { serviço público, assente no tradicional } \\
\text { sistema de emprego; funcionários } \\
\text { com contratos a termo ou por } \\
\text { tempo indeterminado, recrutados } \\
\text { para uma determinada categoria; } \\
\text { poucas hipóteses de promoção ou } \\
\text { mudança de categoria (horizontal e } \\
\text { verticalmente) na organização }\end{array}$ & $\begin{array}{l}\text { Dinamarca, Finlândia, Holanda, } \\
\text { Suécia e Reino Unido }\end{array}$ \\
\hline Tipo 3 & $\begin{array}{l}\text { Não é um sistema de segurança } \\
\text { nem um sistema de flexibilidade; } \\
\text { trata-se de um sistema de emprego } \\
\text { híbrido; Muitas vezes, quando é } \\
\text { introduzida uma maior flexibilidade } \\
\text { para os empregadores contratarem } \\
\text { e demitirem funcionários, o } \\
\text { correspondente aumento na segurança } \\
\text { na transiçáo para os trabalhadores é } \\
\text { esquecido, levando a uma posição } \\
\text { muito insegura para os trabalhadores }\end{array}$ & $\begin{array}{l}\text { Bulgária, Republica Checa, Estónia, } \\
\text { Hungria, Letónia, Lituânia, Polónia, } \\
\text { Roménia, Eslováquia e Eslovénia }\end{array}$ \\
\hline
\end{tabular}

Fonte: Kuperus, H., Rode A. e Duta, R. Trends in Public Administration and the Healthcare Sector, as part of the project "Restructuring in the Public Sector: A Flexicurity Approach" (co-financed by the European Commission), apud Kuperus et al, 2010. Tradução própria.

Há quem defenda que a flexisegurança não é apenas sobre uma maior flexibilidade das regras do mercado de trabalho para o empregador, como muitas vezes é interpretado. A flexisegurança, no plano das ideias, pretende acolher a igualdade de 
direitos e de novas oportunidades, tanto para o empregador como para o empregado, suportada num equilíbrio entre flexibilidade e segurança. É importante que tanto a flexibilidade, como a segurança, sejam implementadas nas administraçôes públicas em paralelo com a modernização do emprego e condiçóes de trabalho (Kuperus et al, 2010). Apesar do que se refere, a introdução da segurança e flexibilidade, também conhecida como técnica de manipulação poderá, segundo muitos, querer ocultar o verdadeiro objectivo, a liberalização dos despedimentos e até, conciliar interesses de classe contraditórios, transformando relações de precariedade laboral num elemento comum na vida dos trabalhadores.

A flexisegurança enquanto forma global de política do mercado de trabalho, que combina disposiçóes contratuais flexíveis, que facultem novas contrataçôes e despedimentos, que defenda a diminuição do emprego para toda a vida, regimes salariais indexados ao desempenho, o fim dos automatismos na progressão e promoção dos trabalhadores, horários semanais flexíveis e a tempo parcial e a antecipação voluntária de reforma, de entre outros, mais não é do que uma panóplia de características que redundam no abandono do sistema de carreira em favor do regime de emprego e, em última instância, a adopção de um modelo de emprego público híbrido, mais apropriado ao século XXI, para onde converge a grande maioria dos países.

\section{CONCLUSÃO}

As assumpçóes teoréticas sobre procedimentos institucionais a propósito das reformas do emprego público, em particular dos tradicionais sistemas de emprego que prevaleceram durante todo o século XX e que se esmorecem no início deste século, parecem ter origens e propósitos muito semelhantes. Qualquer que seja a perspectiva de análise ${ }^{7}$, pelas menos duas posiçóes, extremas, estarão sempre em confronto: de um lado os funcionários públicos na defesa dos seus interesses pessoais e, porventura egoístas (não se discutindo a sua legitimidade) e, do outro, os

\footnotetext{
7 Ver Wessels (1998) a propósito dos pressupostos teóricos sobre a identificação do comportamento dos funcionários públicos no ciclo político da União Europeia, em que o autor apresenta 7 visōes para o problema: Realist view, Federalist view, Neo-functionalist view, Functionalist view, Erosion view, Governance view, Fusion view.
} 
interesses do Estado. Neste confronto (ou não) qualquer um dos agentes poderá assumir uma posiçáo de responsabilidade compartilhada e solidária com o outro. Acontece, porém, que tal parece não ser a solução que tem sido escolhida nas últimas décadas, de onde tem resultado que, face a diferentes adversidades, tem sido o Estado a tomar o governo, impondo, de alguma maneira, a solução para o problema. A pressão entre as partes advém, quase sempre, das tensōes entre a ênfase colocada pelo Estado na descentralização que tem vindo a promover nos modelos de mercado de trabalho e respectiva coordenação no sector público.

Impóe-se, assim, uma estratégica autêntica que prescreva um sistema de emprego público mais flexível aos ciclos económicos a fim de aumentar a capacidade de resposta a longo prazo da administração pública para a mudança e para evitar soluçôes de curto prazo em casos de crise. As administraçóes públicas deverão considerar um anti-cyclic labour market and personnel policy (Kuperus et al, 2009) em todas as suas dimensóes de forma a incrementar políticas responsáveis de longo prazo. Trata-se, assim, de perceber, que o tradicional sistema de carreira, em todas as suas dimensôes, deva ficar limitado a funçóes de soberania (tipicamente estatais), abrangendo um perímetro muitíssimo mais reduzido no seu alcance e que se promovam sistemas muito mais abertos, híbridos portanto, de formas de emprego público flexível, como já fazem, de resto, alguns países.

\section{REFERENCIAS BIBLIOGRÁFICAS}

Aberbach, J. D.; Putnam, R. D.; Rockman, B. A. (1981). Bureaucrats and Politicians in Western Democracies. Cambridge Massachusetts: Harvard University Press.

Adomonis, Vidmantas (2008) Structural Elements of a Law on Civil Service, Trends and Fundamental Choices. Workshop on Building a Professional Civil Service in Kosovo: Support for Improvement in Governance and Management, SIGMA.

Bekke, Hans A. G. M., James L. Perry Theo A. J. Toonen. (1996). "Introduction: Conceptualizing Civil Service Systems". In, Bekke, Hans A. G. M., James L. Perry; Theo A. J. Toonen (editors) Civil Service Systems in Comparative Perspective. Bloomington: Indiana University Press.

Bodiguel, J. L. (1995). "The Civil Service of the European Union" International Review of Administratives Sciences Vol. 61, N³, pp. 433-453.

Bordogna, Lorenzo (2008). "Moral hazard, transaction costs and the reform of public service 
employment relations". Paper $N^{\circ} 19$, Social Dialogue, Labour Law and Labour Administration Branch, Geneva: International Labour Office.

Bourgon, J. (2008). The Public Service of 2025 - Themes, Challenges and Trends: Human Resources Management Trends in OECD Countries. Quebec. http://unpan1.un.org/intradoc/groups/ public/documents/un/unpan034107.pdf

Boyne, George, Jenkins, Glenville and Poole, Michael (1999). "Human Resource Management in the Public and Private Sectors: An Empirical Comparison" Public Administration, Vol. 77, No 2, pp. 407-420.

CE (2006) Livro Verde: Modernizar o direito do trabalho para enfrentar os desafios do século XXI. Comissão das Comunidades Europeias: Bruxelas.

Dahlström, Carl; Lapuente, Victor (2008). "Do You Believe Me? Public Sector Incentive Systems in Japan, Korea, Spain, and Sweden” Working Paper Serie N²5. The Quality of Government institute University of Gothenburg: Sweden. http://www.qog.pol.gu.se/

Dambrine, F. (2002). L'Évolution des corps de la haute fonction publique dans uneperspective européenne. Assemblé Générale de L’Association des Ingéniers des Télécomunications:France.

Demmke, Christoph; Henökl, Thomas; Moilanen, Timo (2008). "What are Public Services Good at? Success of Public Services in the Field of Human Resource Management". Report to the 50th Meeting of the Directors-General of Public Services of the Member States of the European Union. European Institute of Public Administration.

Denhardt, Robert B., ; Denhardt, Janet Vinzant (2000). The New Public Service: Serving Rather than Steering. Public Administration Review. Vol., 60, N 6, pp.549-559

Derlien, H.U. (1994). "Germany: The Structure and Dynamics of the Reward System for Bureaucratic and Political Elites", in Guy Peters (editor) Rewards at the top: a comparative study of high public office. SAGE Publications: Londres.

Desmarais, Celine (2008). "The french research community's perspectives on new public human resource management”. Public Management Review, Vol., 10 N$^{\circ} 1$ pp 139-150.

Eymeri, J. M. (2001). Pouvoir politique et haute administration: une comparaison européenne. European Institute of Public Administration: Netherlands.

Franco, A. S. (1987). Relatório sobre o Sistema Retributivo da Função Pública. Livro Branco Sobre os Sistemas Retributivos da Função Pública em Portugal. Presidência do Conselho de Ministros: Lisboa.

Harel, Gedaliahu; Tzafrir, Shay (2001). HRM Practices in the Public Sector and Private Sectors: Differences and similarities. Technion - Israel's Institute of Technology, PAQ.

Hood, C. (1991). “A Public Administration for all Seasons?” Public Administration, Vol. 69, №1, pp.3-20. 
Kuperus, Herma ; Rode, Anita (2009). "Flexicurity Approach and Restructuring: Part of Strategic Management in Public Administrations in Europe?". Paper to be presented at EGPA Conference. Study Group Strategic Management Theme: Malta.

Kuperus, Herma; Rode, Anita (2010). More efficient civil services in times of economic recession and beyond: can a flexicurity approach help?. European Institute of Public Administration, EIPASCOPE.

Lægreid, Per; Lois Recascino Wise. (2007). Reforming Human Resource Management in Civil Service systems: Recruitment, Mobility, and Representativeness. In Raadschelders, Jos C. N., Theo A. J. Toonen; Frits M. Van der Meer (editors) The Civil Service in the 21st century. Comparative Perspectives. Basingstoke: Palgrave Macmillan.

Levi, Margaret. (2005). Inducing Preferences within Organizations. In ed Katznelson, Ira and Barry R. Weingast. Preferences and Situations: Points of Intersection Between Historical and Rational Choice Institutionalism. New York: Russell Sage Foundation.

Longo, F. (2001). La Reforma del Servicio Civil en las Democracias Avanzadas: Mérito con Flexibilidad. Banco Interamericano de Desarrollo, Red de Gestión Pública y Transparencia: Washington.

Lopes, Albino (2001). O Trabalho em Transformaçâo: Eixos de Mudança e Repercussōes na Gestão de Recursos Humanos na Administraçâo Pública. Instituto Superior de Ciências do Trabalho e da Empresa: Lisboa.

Madureira, César ; Ferraz, David (2010). "The Need of a XXI Century Governance Paradigm for Public Administration: The Specific Case of Portugal”. Public Policy and Administration, No 31, p. 35-48.

Marshall, Gary S.; Coudhury, Enamul (1997). "Public Administration and the Public Interest: RePresenting a Lost Concept”. American Behavioral Scientist Vol., 41; N¹ 119-131.

Mastracci, Sharon H.; Thompson, James R. (2007). "Flexibilized Employment in the Public Sector: Surprising Similarities and Important Differences between the United States and the United Kingdom”. International Journal of Public Administration, Vol., 30, №5, pp. 541-557.

Menchero, M. A. (2002). "O Processo de Recrutamento na Administração Pública: Avaliação do Sistema, do Método e do Procedimento”. A Reinvenção da Função Pública, da Burocracia à Gestão, 3º Encontro INA: Lisboa.

Nomden, K.; Onnee-Abruciati (2002). Labour relations in European public services. Annual meeting of the European group of public administration. Potsdam.

OCDE (1993). L'Évaluation des Performance: Pratique, Problèms et Questions à Débattre. Paris, OCDE: PUMA, Gestion Publique, Université d'Australie Occidentale, Paris.

OCDE (1995). Top Management Service in Central Government: Introducing a System for Higher Civil Service in Central and Eastern European Countries. OCDE/CCET and EC/PHARE, SIGMA: Support for Improvement in Governance and Management in Central and Eastern European Countries. 
OCDE (1997a). Measuring Public Employment in OECD Countries: Sources, Methods and Results. Paris, OCDE: PUMA.

OCDE (1997b). Public Management: Profiles 1992. OCDE: Paris

OCDE (2000). Recent Developments and Future Challenges in Human Resource Management in OECD Member Countries, Background. Paper by the Secretariat. Paris, OCDE: PUMA/HRM 6.

OCDE (2001). Public Sector - An Employer of Choice?. Report on the Competitive Public Employer Project. OCDE - Public Management Service.

OECD (2002). Improving Service Delivery through Public Service Reform: Lessons of Experience from Select Sub-Saharan Africa Countries. Paper submitted by the Chair of the. Donors Working Group on Public Service Reform. DAC Network on Good Governance and Capacity Development. Réseau du CAD sur la bonne gouvernance et le renforcement des capacités.

OECD (2008). Challenges of Human Resources Management for Multi-Level Government. Public Governance and Territorial Development Directorate, Public Governance Committee. Public Employment and Management Working Party. Annual Meeting. Final Draft, OECD Conference Center, Paris.

OECD (2009). Public Employment: Good Practices for Preventing Conflict of Interest. Public Governance and Territorial Development Directorate, Public Governance Committee. Global Forum on Public Governance. OECD: Conference Centre Paris, France.

Osborne, S. (2006). “The new public governance?”, Public Management Review, Vol. 8 N 3, pp. 377-387.

Parrado, Salvador (1996). Controlling the Acess to the Spanish Summit (1938-1993). Paper presented at the Groupe de Travail, Histoire de L'Administration, International Institute of Administrative Sciences, ref. Doc. 66-1996.

Petermann, S. (2001). La Réforme de systèmes politico-administratifs: le cas américan pour éclairer le cas belge?. Universite de Liege, Faculte de Droit, Section de Sciences Politiques: Liege.

Pollitt, Christopher; Geert Bouckaert (2004). Public management reform. A ComparativeAnalysis. Oxford: Oxford University Press.

Saraiva, E. (1997). La situación laboral del personal de la administracion pública. Documentos CLAD.

Truss, Catherine (2009). Changing HR functional forms in the UK public sector. The International Journal of Human Resource Management, Vol., 20, № 4, pp. 717-737.

Wessels, W. (1998). "Comitology: fusion in action. Politico-administrative trends in the EU system”. Journal of European Public Policy, Vol., 5 N², pp. 209-234.

Williamson, Oliver E. (1975). Markets and Hierarchies. New York: Free Press.

Zweifel, Peter; Zaborowski, Christoph (1996). “Employment service: Public or private?”. Public Choice $\mathrm{N}^{\circ} 89$ pp. 131-162.

El artículo fue recibido el 30 de octubre y fue aceptado para su publicación el 15 de diciembre. 